\title{
Original
}

\section{Painful Shoulder Syndrome}

\author{
Galia Constanza Fonseca-Portilla ${ }^{1}$, Sócrates Vargas-Naranjo ${ }^{2}$, Carlos Eduardo Alpízar- \\ Chacón ${ }^{1}$,Ana Yendry Moreno-Cordero ${ }^{1}$
}

${ }^{1}$. MarcialFallasDíaz Clinic.

2. Costa Rican Social Security Authority central headquarters.

Place were this work was carried out: MarcialFallasDíaz Clinic, Desamparados, San José, Costa Rica.

Abbreviations: NSAID, nonsteroidal anti-inflammatory drug; PSS, painful shoulder syndrome.

Correspondence: Galia Fonseca Portilla E-mail: rehabunal@yahoo.com

\section{Abstract}

Aim: a painful shoulder is one of the ten most frequent causes of physiatric consultation and it affects a high percentage of the economically active population. In $2008,5.47 \%$ of the new cases seen the physiatrics service of one of our metropolitan clinics were associated with a painful shoulder. This study looked at the way the painful shoulder syndrome occurs in this populationby assessing the demographic variables of these patients and the treatment strategies applied to them.

Methods: a retrospective analysis of the medical records of 171 patients consulting for painful shoulder syndrome during 2008 at a second-level peripheral metropolitan clinic which serves a population of 400000 inhabitants of rural, marginal urban, and urban areas was carried out.Demographic variables, diagnoses and clinical assessment, medical images, and applied treatments were recorded.

Results: mean age in patients was 55.5 years, with a higher frequency of female individuals $(74.3 \%)$ and right side pain $(45 \%)$. The coexistence of diabetes $(20.9 \%)$ and depressive disorders $(15 \%)$ was confirmed. This work is the first one to identify fibromyalgia (4.3\%) as a simultaneous factor to shoulder pathology. Regarding treatment, high quality interventions including exercise, infiltrations and use of nonsteroidal anti-inflammatory drugs were detected.

Conclusion: many clinical and demographic variables previously described as being associated with painful shoulder syndrome are applicable to this population (gender, age, side of pain, comorbidities). Also, we report a possible relationship between fibromyalgia and shoulder pain. The recording of a quality minimal clinical evaluation of the patients could be improved. The general quality of care given to these patients complies with proposed international minimal standards, although it is advisable to implement protocols for this aspect.

Keywords: painful shoulder, risk factors, ultrasound, infiltration, exercise, diabetes. 
The Painful Shoulder Syndrome (PSS) is a very frequent cause of consultation, with a prevalencebetween $6-11 \%{ }^{1}$ and $36.8 \%{ }^{2}$ in the general population. In the working populationnearly $2 \%$ of the muscular-skeletal diagnosesrelate to shoulder pain. ${ }^{1}$ There are very few publications addressing the frequency and characteristics of this syndrome in Costa Rica. ${ }^{2,4-6}$

A specific and rapid diagnosis of this muscularskeletal condition and the development of a therapeutic scheme aimed at pain alleviation, recovery of functionality and prevention of relapse or the involvement of the contralateral shoulder must guide medical activity in PSS.

In order to better understandthis illness and the affected patients, we conducteda research looking at the identification of specific clinical characteristicsand therapeutic measures undertaken by the physiatrics department in one of our second level (with medical specialties) metropolitan peripheral clinics which serves a population of approximately 400000 inhabitants of rural, marginal urban and urban areas.

\section{Methods}

A cross-sectional observational study of consultations received during 2008 was carried out ina type 3 health facility in Desamparados, San José, CostaRica. All the medical records of patients consulting for PSS, regardless of etiology, who had been seen at the physiatrics service by a specialized medic, were included in the analysis. Records of patients who underwentshoulder surgerybefore 2008, who had hemiplegia, breast disease, tumor history, and those in a wheelchair were excluded from the analysis.

The occurrence of PSS was analyzed in terms of gender, age, occupation, clinical assessment, diagnostic group (according to Marín's proposal), ${ }^{7}$ affected shoulder (left, right, both), concomitant pathologies in patients at the time of diagnosis, medical images (x-ray and ultrasound), and treatment of choice (pharmacologic, non pharmacologic). Data were collected by means of a printed or digital questionnaire.The analysis of the data was done with Epinfo version 3.3.2. and Excel 8.0.

The quality of the database was assessed by examining each variable separately and determining if values were congruent with the original questionnaires. Additionally, incoherent entries were eliminated.

For continuous variables a mean and range were calculated. Proportions were obtained for categorical data.

This study was approved by the institutional Bioethics Committee (CLOBI-CMF-0012009, session 11-04-09).

\section{Results}

After the examination of the medical records of the type 3 health facility, 171 records in which a diagnosis of PSS had been made and that complied with all the inclusion and exclusion criteria were identified.

We found that subjects suffering PSS had attended the physiatrics service for an average of 1.7 years (range $1-5$ years). Moreover, the average annual number of consultations per individual was 3.4. Regarding patient age, an average of 54.5 years and a range of 15 to 90 years were determined. Furthermore, the majority of individuals belonged to the group of $41-70$ years of age (Table 1 ).

A higher proportion of the patients were women $(74.3 \%)$ and most individuals $(80.1 \%)$ had occupations were they performed manual work (cleaners, maids). Other occupations were intellectual activities (7.6\%), mixed activities (e.g. pre-scholar teachers, primary healthcare technician) (7.0\%), pensioners (4.1\%), and unemployed (1.2\%).

We found that $1.8 \%$ of the patients received a physical examination which included their necks, the movement of their shoulders, their pinching signs, and a neurological examination. $96.4 \%$ of the patients received a physical examination which included three or less of these aspects. Additionally, for $1.8 \%$ of the patients no details on the evaluated sites during the physical examination were recorded (Table 1). 
Table 1. Description of variables such as physical examination, concomitant pathology and diagnostic group between subjects suffering PSS in a type 3 health facility, 2008.

\begin{tabular}{|llcc|}
\hline \multicolumn{1}{|c}{ Variable } & \multicolumn{1}{c}{ Category } & N & \% \\
\hline $\begin{array}{l}\text { Physical } \\
\text { examination* }\end{array}$ & All & 165 & 96.4 \\
& 3 or less & 3 & 1.8 \\
& Non specified & 3 & 1.8 \\
Concomitant & Diabetes Mellitus & 27 & 38.6 \\
& & & \\
& Depression & 10 & 14.3 \\
& Psychiatric & 8 & 11.4 \\
& disorder & & \\
& Spondyloarthrosis & 7 & 10 \\
& Digestive system & 11 & 15.7 \\
& Fibromyalgia & 3 & 4.3 \\
& Depressive & 2 & 2.9 \\
& disorder & & \\
& Dementia & 1 & 1.4 \\
& Insomnia & 1 & \\
Siagnostic & Subacromial & 155 & 90.6 \\
group** & syndrome & & \\
& Adhesive capsulitis & 3 & 1.8 \\
& Rupture of rotator & 5 & 2.9 \\
& cuff & & \\
& Painful shoulder & 3 & 1.8 \\
& Other diagnoses & 5 & 2.9 \\
\hline
\end{tabular}

* Assessed aspects: neck, shoulder movement arches, pinching sign, and neurologic exam.

** Clinical diagnosis in PSS.

Source: medical records, type 3 health facility.

Regarding the diagnostic categories accounting for the etiology of the PSS, we found that most records indicated subacromial syndrome (90.6\%),rupture of the rotator cuffand others $(2.9 \%$ each), and adhesive capsulitis and painful shoulder (1.8\% each) (Table 1). Additionally, some patients had two or more diagnoses, some initially having, for example, a bursitis diagnosis but later this being changed for rupture of the rotator cuff or capsulitis.

Most individuals were affected at their right shoulder (45.0\%), whereas the left one (25.1\%) and both shoulders (17.0\%) were less frequent. A proportion of the individuals (12.9\%) had a switching pain in both joints.
Sixty-one (35.7\%) patients were infiltrated, $22.8 \%$ in their right shoulder and $12.9 \%$ in their left shoulder.

Table 2. Results of diagnostic imaging for patients included in the study, type 3 health facility, 2008.

\begin{tabular}{|c|c|c|c|}
\hline $\begin{array}{c}\text { Type of } \\
\text { imaging } \\
\text { test }\end{array}$ & Diagnoses & $\mathbf{N}$ & $\%$ \\
\hline \multirow[t]{10}{*}{ Radiology } & Bilateral arthrosis & 1 & 3.6 \\
\hline & $\begin{array}{l}\text { Scapulo-humeral } \\
\text { arthrosis }\end{array}$ & 1 & 3.6 \\
\hline & $\begin{array}{l}\text { Sclerosis of the } \\
\text { acromion }\end{array}$ & 1 & 3.6 \\
\hline & $\begin{array}{l}\text { Sclerosis of the major } \\
\text { tuberosity }\end{array}$ & 1 & 3.6 \\
\hline & Displaced fragment & 1 & 3.6 \\
\hline & Osteopenia & 1 & 3.6 \\
\hline & Sub-chondral sclerosis & 2 & 7.1 \\
\hline & $\begin{array}{l}\text { Acromio-clavicular } \\
\text { arthrosis }\end{array}$ & 2 & 7.1 \\
\hline & $\begin{array}{l}\text { Cyst of the head of the } \\
\text { humerus }\end{array}$ & 2 & 7.1 \\
\hline & Normal limits & 16 & 57.1 \\
\hline \multirow[t]{8}{*}{ Ultrasound } & $\begin{array}{l}\text { Rupture of the rotator } \\
\text { cuff }\end{array}$ & 17 & 29.3 \\
\hline & Rotator cuff tendinitis & 8 & 13.8 \\
\hline & Bursitis & 7 & 12.1 \\
\hline & $\begin{array}{l}\text { Sprain of the rotator } \\
\text { cuff }\end{array}$ & 4 & 6.9 \\
\hline & Collection & 1 & 1.7 \\
\hline & Pinching & 1 & 1.7 \\
\hline & $\begin{array}{l}\text { Tendinosis of the } \\
\text { rotator cuff }\end{array}$ & 1 & 1.7 \\
\hline & Normal limits & 19 & 32.8 \\
\hline
\end{tabular}

Source:medical records, type 3 health facility.

Concomitant pathologies most commonly seen with PSS were:diabetes mellitus (38.6\%), depression (14.3\%), psychiatric disorders (11.4\%), spondyloarthrosis $(10.0 \%)$, gastritis $(8.6 \%)$, colitis (7.1\%), and fibromyalgia (4.3\%) (Table 1).On the other hand, there was a subset of individuals $(n=59)$ who presentedwith gonarthrosis, spondylitis and convulsions, and,as a whole, accounted for $84.3 \%$.

X-ray studies were presentin $15.8 \%$ of the records, whereas ultrasonography was observed in $33.3 \%$. Both exams yielded varied diagnoses (Table 2). 
Nevertheless, an imaging diagnosis of "study within normal limits" accounted for $57.1 \%$ and $32.8 \%$ of the test results, respectively (Table 2 ).

Regarding treatment, we found that topical therapy and oral nonsteroidal anti-inflammatory drugs (NSAID) were the most common prescriptions to these patients $(67.3 \%$ and $51.5 \%$, respectively),followed by acetaminophen (36.8\%) and rectal NSAID (2.9\%). $54,4 \%$ of the individuals received another pharmacological treatment for their pain.Additionally, $93 \%$ of the patients were issued a recommendation to excercise, and physical therapy was recommended for for $36.3 \%$. Moreover, the majority of the referrals done by the attending physician were to Orthopedics (21.1\%), followed by Psychology (14\%), Psychiatry (5.3\%) and other specialties (2.9\%).

\section{Discussion}

The findings of this study in terms of demographic variables, types of diagnoses, and therapeutic managementbear great similarity to those reported in other publications. ${ }^{1,2,8,9} \mathrm{We}$ and others have found that most patients are women $(74.3 \%)$, a fact that suggests a role for the internal and external activities women perform for their households. 8,10

We also confirm that the right shoulder is the most frequently affected (45\%), possibly due to the preeminence of right-handed population. ${ }^{8} \mathrm{Of}$ interest was the fact that $29.9 \%$ of the patients had a simultaneous or switching pain involving their two shoulders which underscores the importance of preventive measures for the contralateral shoulder.

With respect to the working population, most of the patients ( $80 \%$ ) had manual occupations as has been previously described by others, ${ }^{1,11-19}$ where they are exposed to biomechanical and socio-environmental risks.

The patients presenting with subacromial syndrome constitued the most frequent diagnostic group. This was also reported by Marín ${ }^{7}$ and other groups, $^{20}$ underscoring the importance of this recurrent condition for clinicians. ${ }^{20,21}$
Regarding the duration of the medical attention (20 months), it is similar to that reported by Huisstede ${ }^{2}$ in Europe. The average number of visits to the specialist during those 20 months was 3.4 , but these seem not to be consistent in terms of the minimal clinical aspects to be evaluated during the physical exam, such as the neck, shoulder movement arches, pinching sign and neurological exam. $^{1,2,6,7}$

The behaviour of the population assigned to this clinic in San José confirms the fact that diseases which pose a risk factor for PSS are present within it. All these comorbidities have already been reported in the literature..$^{2,11,14,15}$ I

In this study, fibromyalgia appears to be another important comorbidity for PSS as it was seen in $4.3 \%$ of the cases. There is no mention to this condition as a comorbidity in the reviewed literature. New studies will be required to explore an association between fibromyalgia and PSS.

The literature reports that the ultrasound is the preferred initial exam for PSS. Two thirds of the analyzed patients lacked this test, impairing the assessment of the condition, especially when a rupture of the rotator cuff is present. ${ }^{7,23,24}$

Regarding the current management guidelines for this syndrome, this clinic follows international guidelines, ${ }^{7}$ such as recommendation to exercise, ${ }^{1,7,8,25}$ and infiltration ${ }^{1,7,26}$ in $35.7 \%$ of the cases (in contrast with the subacromial syndrome being present in $90.6 \%$ of the cases).

Topical (67.3\%) and oral (51.5\%) NSAID $^{1,7,8,25}$ were used. Physical therapy was requested for $36.3 \%$ of the cases. This low proportion of physical therapy prescriptions could be due to the fact that this clinic does not have a physiotherapist and patients have to be referred to the San Juan de Dios Hospital.

The results of the physical examination of these patients must include the internationally recommended parameters and these must be recorded.This was something that is not being done systematically nor following any protocols., 6,10,27-29 Finally, the registry of the therapies used by medics 
on these patients must be systematized and strengthened.

\section{References}

1. Ministerio de la Protección Social. Republica de Colombia. Guía deatención integral basada en la evidencia para hombro doloroso (GATIHD) relacionado con factores de riesgo en el trabajo. ISBN 978-958-8067-1-5. Bogotá. Diciembre 2006

2. Huisstede BMA, Wijnhoven HA, Bierma-Zeinstra SM, Koes BW,Verhaar J, Picavet S. Prevalence and characteristics of complaints ofthe arm neck and or shoulder (CANS) in the open population.Clin JPain 2008; 24:253-259.

3. Mora-Vargas K. Hombro doloroso y lesiones del manguito rotador.Caso clinico. Acta Méd Costarric 2008; 50:251-253.

4. Udaondo-Cascante MA, Romero $\mathrm{G}$ de $\mathrm{T}$, Casado $\mathrm{V}$. El hombro dolorosoa través del razonamiento clínico. MEDIFAM 2003; 13:186-190.

5. Rodríguez- J L. Dolor osteomuscular y reumatológico. Rev Soc EspDolor 2004; 11:94-102.

6. Ortiz Corredor F. Evaluación y tratamiento del dolor músculoesquelético común. En Fonseca GC, Manual de Medicina deRehabilitación. Segunda edición. Bogotá, Colombia 2008; 289-291.

7. Marín- M, Navarro MJ, Peiro S., Trenor-Gomis C, Paya-Rubio A,Bernal-Delgado E , Hernandez-Royo A. La calidad de la atención alhombro doloroso. Audit Clínico Gac Sanit 2006; 20:116-23.

8. Schadeck de Almeida J, Carvalho G, Lamari N M. Rotator cuffdisease: aspects and implications. Int JMorphol 2005; 23:381-385.

9. Lin JC, Weintraub N, Aragaki DR.Nonsurgical treatment for rotatorcuff injury in the elderly. J Am Med Dir Assoc 2008;9:626-32.

10. Camargo PR, Haik, MN, Filho RB, Mattiello R, Salvini TF.Pain inworkers with shoulder impingement syndrome:an assessment usingthe
DASH and Mc Gill pain questionnaires. Rev Bras Fisioter2007;11:161-167.

11. Silverstein B, Bao S, Fan Z,Howard N,Smith C, Spielholz $\mathrm{P}$, BonautoD,Vilkari-Juntura E. ROTATOR CUFF syndrome:Personal, workrelatedpsychosocial and physical load factors. JOEM 2008; 50:10621076.

12. Ward S, Hentzen E, Smallwood, Eastlack RK, Burns K, Fithian D,Friden J, Lieber R. Rotator cuff muscle architecture, implications forglenohumeral stability. Clin Orthop Relat Res 2006; 448:1587-163.

13. Mehlum IS, Kristensen P, Kjuus H, Wergeland E . Are occupationalfactors important determinants of socioeconomic inequalities inmusculoskeletal pain? Scand J Work Environ Health 2008; 34:235-8.

14. Norman K, Floderus B, Hagman M, Toomingas A, Tornqvist EW.Musculoeskeletal symptoms in relation to work exposures at callcentre companies in Sweden. Work 2008; 30:201-14

15. Chebli C, Matsen F A. Rotator cuff failure and treatment. Curr OpinOrthop 2006; 17:310-315.

16. ShresthaBp.Sing GK, Niraula SR. Work related complaints amongdentists. JNMA J Nepal Med Assoc 2008; 47:77-81.

17. Byun $\mathrm{YH}$, Lee JH, Park $M K$, Song JH, MInBH, Chang DK, KimYH,SonHJ,RheePI,KIm JJ, Rhee JC, Hwang JH,ParkDI,Shim SG, Sung IK. Procedurerelated musculoskeletal symptoms ingastrointestinal endoscopists in Korea.World J Gastroenterol 2008;14:4359-64.

18. Alipour A, Ghaffari M, Shariati B, Jensen I, Vingard E. Occupationalneck and shoulder pain among automobile manufacturing workers inlran. Am J Ind Med 2008; 51:372-9.

19. Lorusso A, Bruno S, Labbate N.Musculoeskeletal complaints amongltalian X-ray technologists. Ind Health 2007; 45:705-8.

20. Andres B, Murrell G A C.Shoulder.The biology of rotator cuff tears.Current. Orthopaedic Practice 2008; 19:516-523. 
21. Gallo R, Sciulli R, DaffnerR.Defining the

relationship between cuffinjury and proximal humerus fractures. ClinOrthopRelat Res 2007;458: 70-77.

22. Thomas SJ, McDougall C, Brown ID, Jaberoo $M C$, Stearns A,AshrafR. Prevalence of symptoms and signs of shouder problems in peoplewith diabetes mellitus. J Shoulder Elbow Surg 2007; 16:748-51.

23. Nogueira MH, VolponJB ,Elias J, Mucillo G. Diagnostic imaging ofshoulder rotator cuff lesions. Acta Ortop Bras 2002;10:31-39.

24. Milgrom C, Novack V, Weil Y, Jaber S, Radeva $D R$. FinestoneA.Riskfactors for idiopathic frozen shoulder. Isr Med Assoc J2008:10:361-4.

25. Blansted AK, Sogaard $K$, Hansen ES, Hannerz $H$, Sjogaard G. One-year randomized controlled trial with different physical-activityprograms to reduce musculoskeletal symptoms in the neck andshoulders among office workers. Scand J Work Environ Health 2008;34:55-65.

26. Chavero V, Salguero O, Lopez $P$, Álvarez Montero S. Tratamientodel hombro doloroso: ¿antiinflamatorio no esteroideo (AINE) oinfiltración? Revisión crítica de la práctica clínica. MEDIFAM 2002;12: 341-343.

27. Lopes AD, Ciconelli RM, Carrera EF. Validity and reliability of thewestern Ontario rotator cuff index (WORC) for use in Brazil. SportMed 2008; 18:266272.

28. De Winter AF, Van Der Heijden GJ, Schoten RJ, Van Der Windt DA,Bouter LM. The Shoulder disability questionnaire differentiated wellbetween high and low disability levels in patients in primary care, in across-sectional study. J ClinEpidemiol 2007;60:1156-63.

29. Ekeberg Om, Bautz-Holter E, Tveita EK, Keller A, Juel NG, Brox JI.Agreement reliability and validity in 3 shoulder questionnaires in patients with rotator cuff disease. BMC Musuloskelet Disord 2008;15:968. 